\title{
ABSTRAK \\ PENGARUH RANGE OF MOTION (ROM) TERHADAP PENINGKATAN KEKUATAN OTOT PADA PASIEN STROKE DI RUANG PERAWATAN RSUD POLEWALI MANDAR
}

\author{
M.Syikir ${ }^{1}$, Rusman $^{2}$, Andi $^{3}{ }^{\text {Ratnawati }}{ }^{4}$
}

Hasil-hasil studi dibidang neurologimenyatakan bahwa stroke merupakan penyebab kematian nomor satu diberbagai rumah sakit di tanah air (Batticaca, 2012). Menurut taksiran WHO, sebanyak 20,5juta jiwa di dunia sudah terjangkit stroke tahun 2015. Dari jumlah tersebut 5,5 jutajiwa telah meninggal dunia.Sebesar80\%pasienstroke mengalami kelemahan pada salah satu sisi tubuhnya/hemiparese(Ariani, 2012). Kelemahantanganmaupunkakipada pasien stroke akanmempengaruhikontraksiotot, sehingga salah satuprogram rehabilitasi yang dapat diberikan pada pasien strokeyaitumobilisasipersendian dengan latihan range of motion (Potter and Perry, 2010).Tujuan Penelitian ini adalah untuk menganalisis pengaruh ROM terhadap peningkatan fungsikekuatan otot pada pasien stroke di Ruang Perawatan RSUDPolewali Mandar.

Metode Penelitian, yang digunakan adalah metode Quasi Experiment dengan menggunakan rancangan eksperimen Equivalent group (randomized pretest-posttest with control group). Penelitian ini mengambil sampel 10 psien stroke dengan hemiparases 5 kelompok intervensi dan 5 kelompok kontrol, yang mana tekhnik pengambilan sampel secara tehnik accidental sampling yaitu peneliti mengumpulkan data dari subyek yang ditemuinya saat itu dan dalam jumlah secukupnya, dimana Alat Ukur yang digunakan ialah Lembar Observasi dengan Manual Muscle Testing (MMT). Yang mana dianalisis menggunakanuji paired sample test berpasangan dengan tingkat signifikansi $\alpha=0,05$.

Hasil Penelitian, uji statistik didapatkan bahwa kelompok intervensi $(\mathrm{P}=0,000)$ mempunyai pengaruh pemberian ROM dalam peningkatan kekuatan otot dan kelompok kontrol $(\mathrm{P}=0,178)$ tidak mempunyai pengaruh.

Berdasarkan hasil penelitian menunjukkan dengan pemberian latihan ROM, akan mempengaruhi kekuatan otot pada pasien stroke dengan hemiparases. Sehingga sangat di harapkan agar tenaga kesehatan khususnya perawat dapat lebih intensif memebrikan ROM pada pasien stroke dengan hemiparases

Kata Kunci : Range Of Motion, Kekuatan otot, Stroke.

Kepustakaan : 37 buku dari tahun 2008-2017, 3 Artikel dari Internet

\author{
ABSTRACT \\ EFFECT OF RANGE OF MOTION (ROM) ON INCREASING MUSCLE STRENGTH IN STROKE \\ PATIENTS IN THE CARE \\ OF POLEWALI MANDAR HOSPITAL
}

M.Syikir ${ }^{1}$, Rusman $^{2}$, Andi $^{3}{ }^{2}$ Ratnawati $^{4}$ 
(5 Chapters, 75 Pages + iii +8 Attachments)

The results of studies in the field of neurology state that stroke is the number one cause of death in various hospitals in the country (Batticaca, 2012). According to WHO estimates, as many as 20.5 million people in the world have contracted strokes in 2015. Of these 5.5 million people have died. About $80 \%$ of stroke patients experience weakness on one side of their body / hemiparese (Ariani, 2012). Weakness of the hands and feet in stroke patients will affect muscle contraction, so one rehabilitation program that can be given to stroke patients is the mobilization of joints with range of motion exercises (Potter and Perry, 2010).

The purpose of this study was to analyze the effect of ROM on the improvement of muscle strength function in stroke patients in the Polewali Mandar General Hospital Treatment Room.

The Research Method, which is used is the Quasi Experiment method using the Equivalent group experimental design (randomized pretest-posttest with control group). This study took a sample of 10 stroke patients with hemiparases 5 intervention groups and 5 control groups, in which the sampling technique was accidentally sampling technique, namely the researcher collected data from the subjects he met at that time and in sufficient quantities, where the measuring instrument used was Observation Sheet with Manual Muscle Testing (MMT). Which is analyzed using paired sample test in pairs with a significance level of $\alpha=0.05$.

Research results, statistical tests found that the intervention group $(\mathrm{P}=0,000)$ had the effect of giving ROM in increasing muscle strength and the control group $(\mathrm{P}=0.178)$ had no effect.

Based on the results of the study showed that administration of ROM exercise, will affect muscle strength in stroke patients with hemiparases. So that it is highly expected that health workers, especially nurses, can be more intensive in giving ROM to stroke patients with hemiparases

Keywords: Range Of Motion, Muscle Strength, Stroke.

Literature: 37 books from 2008-2017, 3 articles from the Internet

\section{PENDAHULUAN}

\section{LatarBelakang}

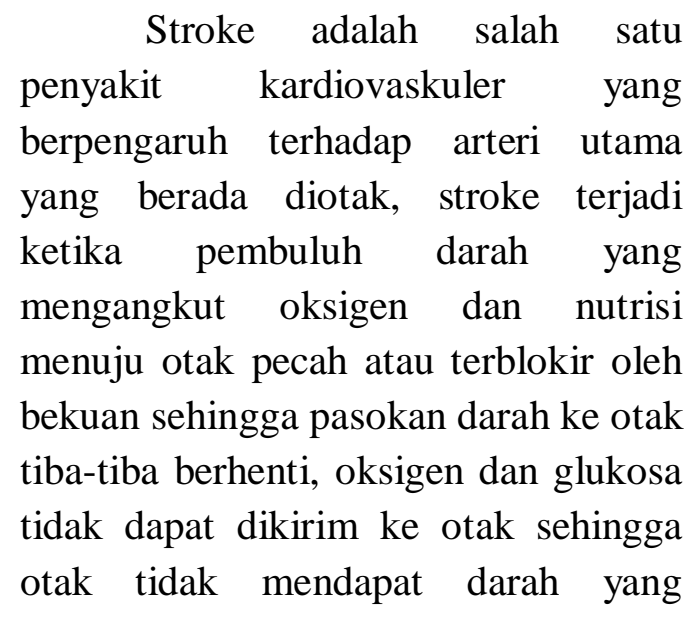

dibutuhkannya. Jika kejadian berlangsung lebih dari 10 detik akan menimbulkan kerusakan permanen otak(Soeharto,2014).

Terhambatnya penyediaan oksigen dan nutrisi ke otak menimbulkan masalah kesehatan yang serius karena dapat menimbulkan hemiparese bahkan kematian. Stroke merupakan penyabab kematian ketiga tersering setelah penyakit jantung koroner dan kanker. Limabelasorang diseluruh dunia terserang stroke setiap tahun, lima juta meninggal dan lima 
juta lainnya menderita kecacatan (Price\&Wilson, 2016)

Stroke merupakan salah satu masalah kesehatan yang cukup serius dalam kehidupan modern saatini,Prevalensi stroke meningkat seiring dengan bertambahnya usia. Padausia 18-44 tahun prevalensinya meningkatsebesar $0,8 \%$ danpada usia 65 tahun keatas meningkat $8,1 \%$ (American Heart Association, 2009)

Badan Kesehatan se-Dunia (WHO) memperkirakan sekitar 15 juta orang terkena stroke setiap tahunnya. Stroke merupakan penyebab kematian utama urutan kedua pada kelompok usia diatas 60 tahun. Negara-negara miskin dan berkembang, seperti Indonesia, insiden stroke cenderung meningkat setiap tahunnya meskipun sulit mendapat data yang akurat.(Alchuriyah \& Wahjuni, 2016)

Hingga kini, stroke merupakan penyebab kematian nomor satu diberbagai rumah sakit di tanah air (Batticaca, 2012). Menurut taksiran WHO, sebanyak 20,5juta jiwa di dunia sudah terjangkit stroke tahun 2015. Dari jumlah tersebut 5,5 jutajiwa telah meninggal dunia. Penyakit darah tinggi atau hipertensimenyumbangkan 17,5 juta kasus stroke di dunia. Di Indonesia penyakit inimenduduki posisi ketiga setelah jantung dan kanker. Sebanyak $28,5 \%$ penderitameninggal dunia dan sisanya menderita kelumpuhan sebagian atau total.Hanya15\% saja yang dapat sembuh total dari serangan stroke dan kecacatan (Lloyd et al, 2009).

Berdasarkan penelitian Riset Kesehatan Dasar tahun2017di33provinsi dan 440 kabupaten dilndonesia diperoleh hasilbahwa penyakitstroke merupakan pembunuh utama dikalangan penduduk perkotaan. Secara kasar,setiap hari ada dua orang Indonesia mengalami serangan stroke (Rikesdas, 2017).

$\begin{array}{ccc}\text { Stroke } & \text { adalah } & \text { salah } \\ \text { satupenyakit } & \text { kardiovaskuler } & \text { yang }\end{array}$ berpengaruh terhadap arteri utama yang beradadiotak,stroke terjadi ketika pembuluh darah yang mengangkut oksigen dan nutrisi menuju otak pecah atau terblokir oleh bekuan sehingga pasokan darahke otaktiba-tiba berhenti,oksigendanglukosa tidakdapat dikirim ke otak sehingga otak tidak mendapat darah yang dibutuhkannya. Jika kejadian berlangsunglebih dari 10 detik akan menimbulkan kerusakan permanen otak (Soeharto, 2014).

Sebesar $80 \%$ pasienstroke mengalami kelemahan padasalah satu sisi tubuhnya/hemipares (Ariani, 2012). Kelemahan tangan maupun kaki pada pasien stroke akan mempengaruhi kontraksi otot. Berkurangnya kontraksi otot disebabkan karena karberkurangnya suplai darah ke otak belakang danotak tengah, sehingga dapat menghambat hantaran jaras-jaras utama antara otak dan medula spinalis. Kelainan neurologis dapat bertambah karena pada stroke terjadi pembengkakan otak (oedema serebri) 
sehingga tekanan didalam rongga otak meningkat hal ini menyebabkan kerusakan jaringan otak bertambah banyak. Oedema serebri berbahaya sehingga harus diatasi dalam 6jam pertama $=$ Golden Periode $($ Gorman, $M$ et.,al, 2014).

Penderita stroke perlu penanganan yang baik untuk mencegah kecacatan fisik dan mental. Sebesar 30\%-40\% penderita stroke dapat sembuh sempurna bila ditangani dalam waktu 6 jam pertama (golden periode), namun apabila dalam waktutersebutpasienstroke tidak mendapatkanpenangananyang

maksimal maka akan terjadi kecacatan atau kelemahan fisik seperti hemiparese. Penderita stroke post serangan membutuhkan waktu yang lama untuk memulihkan dan memperoleh fungsi penyesuaian diri secara maksimal. Terapi dibutuhkan segera untuk mengurangi cedera cerebrallanjut, salah satu program rehabilitasi yang dapat diberikan pada pasien stroke yaitu mobilisasi persendian dengan latihanrange of motion (Potter and Perry, 2010).

Rangeof motion (ROM) adalah latihan yang dilakukanuntuk mempertahankan atau memperbaiki tingkat kesempurnaan kemampuan pergerakkan sendi secara normal dan lengkap untuk meningkatkan massaototdantonus otot. Melakukan mobilisasi persendian dengan latihan ROM dapat mencegah berbagai komplikasi seperti nyerikarena tekanan,kontraktur, tromboplebitis, dekubitus sehingga mobilisasi dini penting dilakukan secara rutin dan kontinyu. Memberikan latihan ROMsecara dini dapat meningkatkan kekuatan otot karena dapat menstimulasi motor unit sehingga semakin banyak motor unit yang terlibat maka akan terjadi peningkatan kekuatan otot, kerugian pasien hemiparese bila tidak segera ditangani maka akan terjadi kecacatan yang permanen (Potter\&Perry, 2010)

Sejalan dengan penelitian yang dilakukan Sukmaningrum(2012) yang meneliti tentang Efektivitas Range Of Motion Aktif-Asistif : Spherical Grip Terhadap Peningkatan Kekuatan Otot Ekstremitas Atas Pada Pasien StrokeDiRSUD Tugurejo Semarang. Pelaksanaan mobilisasi persendian dengan latihan ROM aktif dan pasif pada penelitian ini dilakukan selama 7 hari dengan perlakuan 2 kali sehari yaitu pagi dan sore hari. Kekuatan otot sesudah terapi latihan gerakjauh lebihtinggi dibandingkan sebelum terapi, dalam artiter jadi kenaikan baikpada hemiparese kanan maupun kiri.Secara statistik dengan menggunakan uji statistik Wilcoxon Match Pairs diperoleh hasil $(\mathrm{p}<0,05)$. Yaitu terdapat perbedaan yang bermakna nilai kekuatan otot antara sebelum dan sesudah diberiperlakuan pada pasien stroke hemiparese kanan maupun kiri.Perbedaan penelitian ini dengan penelitian sebelumnya yaitu pada penelitian iniototyang dilatih ROMtidak terbatas pada ekstremitas 
atas saja namun lebih luas pada ekstremitas atas dan bawah, dan latihan ROM dilakukan selama tujuh hari dengan frekuensi satu kalisehari sehingga lebih menghemat waktu dan tenaga. Untuk itu perlu dilakukan penelitian lebih lanjutapakah dengan latihan ROM selama tujuh hari dengan frekuensi satukali sehari bisa meningkatkan kekuatan otot pasien hemiparese post stroke. Penelitian ini dilakukan diRSUD Polewali Mandar karena RSUD Polewali Mandar merupakan RS rujukan diProvinsi Sulawesi Barat.

Berdasarkan data rekam medik RSUD Polewali Mandar pada tahun 2015 dari 16.082 pasien yang di rawat dengan penyakit stroke 445 pasien yang tersiri dari 345 pasien dengan Non Hemoragik Stroke (NHS) dan 100 pasien dengan Hemoragik Stroke (HS) dan pada tahun 2016 dari 18.986 pasien yang di rawat dengan penyakit stroke 410 pasien yang terdiri dari 325 pasien dengan NHS dan 85 pasien dengan HS sedangkan pada bulan januari sampai bulan Oktober 2017

\section{METODE PENELITIAN}

Dalam penelitian ini, desain atau rancangan penelitian yang digunakan adalah Desain Quasi Experiment dengan menggunakan rancangan eksperimen Equivalent group (randomized pretest-posttest with control group).Dalam desain ini, kedua kelompok (kelompok eksperimen dan kelompok kontrol) dilakukan pengukuran sebelum dilakukan dari 18.422 pasien dengan penyakit 511 pasien yang terdiri dari 393 NHS dan 128 pasien dengan HS.

Berdasarkan hasil studi pendahuluan yang dilakukandiRSUD pada bulanDesember 2017 dengan wawancara ke beberapa perawat di ruang perawatan mengatakan bahwa pasien stroke dengan hemiparase tidak pernah melakukan intervensi tekhnik ROM kepada pasien ia mengatakan bahwa "pasien dengan hemiparase di bawa ke ruang fisioterapi itupun kalau ada isntruksi dari dokter saraf', dan melakukan wawancara kepada keluarga pasien stroke dengan hemiparase, keluarga mengatakan tidak pernah perawat menganjurkan ataupun melakukan teknik ROM pada pasien, hal ini tentu sangat memprihatinkan dimana pasien membutuhkan penanganan segera terutama dalam hal rehabilitasi dan latihan gerak maka, penulis tertarik untuk melakukan penelitian tentang "PengaruhROM Terhadap Peningkatan fungsi Kekuatan Otot pada Pasien Strokedi Ruang Perawatan RSUD Polewali Mandar" exposure / experimental treatment dan setelah exposure / experimental treatment.Namun pada kelompok control tidak dilakukan exposure / experimental treatment, hanya dilakukan pada kelompok eksperimen(Saryono, 2011; Pamungkas, Rian Adi 2017). Desain penelitian ini dapat digambarkan sebagai berikut : 


$\begin{array}{cccc}\text { Group } & \text { Pretest } & \text { Intervensi } & \text { Posttest } \\ \text { Eksperiment } & \mathrm{O} 1 & \mathrm{X} & \mathrm{O} 2 \\ \text { Kontrol } & \mathrm{O} 1 & - & \mathrm{O} 2\end{array}$

Keterangan :

\section{Gambar 3.2 Desain Penelitian}

$\mathrm{O} 1$ = Penilaian kekuatan otot pre test

$\mathrm{O} 2$ = Penilaian kekuatan otot post test

$\mathrm{X}=$ Intervensi ROM

- $\quad$ = Tanpa intervensi ROM

\section{HASIL PENELITIAN DAN PEMBAHASAN}

\section{Hasil Penelitian}

\section{Karakteristik Demografi Responden}

\section{Umur}

Umur dihitung berdasarkan usia terakhir pada saat bertemu responden. Pengelompokkan umur dengan interval limatahunan berdasarkan interval umur terendah yaitu 45-50 tahun dengan umur tertinggi yaitu 56-60 tahun. Distribusi responden berdasarkan umur dapat dilihat pada tabel di bawah ini :

Tabel 4.1.Gambaran Distribusi Responden Berdasarkan Umur Pada Kelompok Intervensi dan Kontrol

\begin{tabular}{cccccc}
\hline & & \multicolumn{4}{c}{ Kelompok } \\
\cline { 3 - 6 } No. Umur & \multicolumn{2}{c}{ Intervensi } & \multicolumn{2}{c}{ Kontrol } \\
\cline { 3 - 6 } & & $\mathbf{F}$ & $\mathbf{\%}$ & $\mathbf{F}$ & $\mathbf{\%}$ \\
\hline 1 & $45-50$ & 2 & 40 & 2 & 40 \\
2 & $51-55$ & 2 & 40 & 2 & 40 \\
3 & $56-60$ & 1 & 20 & 1 & 20 \\
\hline \multicolumn{2}{c}{ Jumlah } & $\mathbf{5}$ & $\mathbf{1 0 0}$ & $\mathbf{5}$ & $\mathbf{1 0 0}$ \\
\hline
\end{tabular}

Sumber : Data Primer Tahun 2018

Dari Tabel 4.1 diatas dapat diketahui bahwaumur responden dalam rentang sama antara kelompok intervensi dan kontrol yaitu umur 45-50 tahun sebanyak 2 orang (40\%), umur 51-55 tahun sebanyak 2 orang (40\%) dan umur 56-60 tahun sebanyak 1 orang $(20 \%)$. 


\section{Jenis Kelamin}

Jenis kelamin merupakan pembeda atara manusia satu dengan manusia yang lain yang memiliki ciri-ciri fisik yang berbeda. Distribusi responden berdasarkan jenis kelaminresponden dapat dilihat pada tabeldi bawah ini:

\section{Tabel 4.2.Gambaran Distribusi Responden Berdasarkan Jenis KelaminPada Kelompok Intervensi dan Kontrol}

\begin{tabular}{cccccc}
\hline \multirow{2}{*}{ No. Jenis } & \multicolumn{4}{c}{ Kelompok } \\
\cline { 3 - 6 } & Kelamin & \multicolumn{2}{c}{ Intervensi } & \multicolumn{2}{c}{ Kontrol } \\
\cline { 3 - 6 } & & F & $\mathbf{\%}$ & F & \% \\
\hline 1 & Laki-Laki & 2 & 40 & 3 & 60 \\
2 & Perempuan & 3 & 60 & 2 & 40 \\
\hline \multicolumn{2}{c}{ Jumlah } & $\mathbf{5}$ & $\mathbf{1 0 0}$ & $\mathbf{5}$ & $\mathbf{1 0 0}$ \\
\hline
\end{tabular}

Sumber : Data Primer Tahun 2018

Dari tabel 4.2 diatas dapat diketahui bahwa jumlah responden pada kelompok intervensi dengan jenis kelamin laki-laki sebanyak 2 orang (40\%) dan perempuan sebanyak 3 orang $(60 \%)$ sedangkan kelompok kontrol responden dengan jenis kelamin laki-laki sebanyak 3 orang $(60 \%)$ dan perempuan sebanyak 2 orang $(40 \%)$.

\section{Pekerjaan}

Pekerjaan merupakan sumber penghasilan responden. Semakin besar penghasilan seseorang maka keinginan untuk memilih sarana pelayanan kesehatan yang terkait dengan pembiayaan akan semakin luas. Distribusi responden berdasarkan pekerjaanresponden dapat dilihat pada tabeldi bawah ini:

Tabel 4.3.Gambaran Distribusi

RespondenBerdasarkanPekerjaanPada Kelompok Intervensi dan Kontrol

\begin{tabular}{lll}
\hline No. & Pekerjaan & Kelompok \\
\hline
\end{tabular}




\begin{tabular}{cccccc}
\hline & & \multicolumn{2}{c}{ Intervensi } & \multicolumn{2}{c}{ Kontrol } \\
\cline { 3 - 6 } & & F & $\mathbf{\%}$ & F & \% \\
\hline 1 & Petani & 2 & 40 & 1 & 20 \\
2 & URT & 1 & 20 & 1 & 20 \\
3 & Wiraswasta & 2 & 40 & 2 & 40 \\
4 & Wirausaha & 0 & 0 & 1 & 20 \\
\hline \multicolumn{2}{c}{ Jumlah } & $\mathbf{5}$ & $\mathbf{1 0 0}$ & $\mathbf{5}$ & $\mathbf{1 0 0}$ \\
\hline
\end{tabular}

Sumber : Data Primer Tahun 2018

Dari tabel 4.3 diatas dapat diketahui bahwa jumlah responden pada kelompok intervensi dengan pekerjaanPetani sebanyak 2 orang (40\%), URT 1 orang (20\%) dan Wiraswasta sebanyak 2 orang $(40 \%)$ sedangkan kelompok kontrol responden dengan pekerjaanpetani sebanyak 1 orang (20\%), URT sebanyak 1 orang (200\%), Wiraswasta sebanyak 2 orang (40\%) dan Wirausaha sebanyak 1 orang (20\%).

\section{Alamat}

Alamat merupakan tempat tinggal atau rumah yang merupakan tempat beristirahat dan bercengkrama dengan keluarga yang terdiri dari nama desa atau lingkungan.Distribusi responden berdasarkan alamatresponden dapat dilihat pada tabeldi bawah ini:

Tabel 4.4.Gambaran Distribusi Responden Berdasarkan AlamatPada Kelompok Intervensi dan Kontrol

\begin{tabular}{cccccc}
\hline & & \multicolumn{4}{c}{ Kelompok } \\
\cline { 3 - 6 } No. & Alamat & \multicolumn{2}{c}{ Intervensi } & \multicolumn{2}{c}{ Kontrol } \\
\cline { 3 - 6 } & & F & \% & F & \% \\
\hline 1 & Pekkabata & 1 & 20 & 1 & 20 \\
2 & Polewali & 3 & 60 & 2 & 40 \\
3 & Tanro & 1 & 20 & 0 & 0 \\
4 & Majene & 0 & 0 & 1 & 20 \\
5 & Mambi & 0 & 0 & 1 & 20 \\
\hline & Jumlah & $\mathbf{5}$ & $\mathbf{1 0 0}$ & $\mathbf{5}$ & $\mathbf{1 0 0}$ \\
\hline
\end{tabular}

Sumber : Data Primer Tahun 2018

Dari tabel 4.4diatas dapat diketahui bahwa jumlah responden pada kelompok intervensi dengan
Alamatpekkabata sebanyak 1 orang (20\%), Polewali sebanyak 3 orang (60\%) dan tanro sebanyak 1 orang 
(20\%). Sedangkan kelompok kontrol responden dengan alamat Pekkabata sebanyak 1 orang $(20 \%)$, Polewali 2 orang (40\%), Majene 1 orang (20\%) dan Mambi sebanyak 1 orang (20\%).

\section{Analisa Univariat}

Pada bagian ini akan disajikan hasil peningkatan fungsi kekuatan otot pada responden yang diberi Range Of Motion(ROM) dengan yang tidak diberikan ROM di Ruang Perawatan RSUD Kabupaten Polewali Mandar.

Peningkatan fungsi kekuatan otot pada pasien stroke sebelum dan sesudah intervensi pada kelompok intervensi dan kelompok kontrol.

Berikut ini akan di sajikan mengenai distribusi kemampuan kekuatan otot ekstremitas responden sebelum dan sesudah dilakukan intervensi pada kelompok intervensi dan kontrol sebagai berikut :

Tabel 4.5.Distribusi Kemampuan Kekuatan Otot Ekstremitas Responden Sebelum dan Sesudah Dilakukan Intervensi Pada Kelompok Intervensi dan Kontrol di Ruang Perawatan RSUD Polewali Mandar

\begin{tabular}{llcccccc}
\hline No & $\begin{array}{l}\text { Kelompok } \\
\text { / Waktu }\end{array}$ & Min & Mak & Mean & Median & SD & CI 95\% \\
\hline 1 & Intervensi & & & & & & \\
& Sebelum & 0 & 3 & 1,6 & 2 & 1,140 & $0,18-3,02$ \\
& Sesudah & 1 & 5 & 3 & 3 & 1,581 & $1,04-4,96$ \\
2 & Kontrol & & & & & & \\
& Sebelum & 0 & 3 & 1,6 & 2 & 1,140 & $0,18-3,02$ \\
& Sesudah & 0 & 3 & 2 & 2 & 1,225 & $0,48-3,52$ \\
\hline
\end{tabular}

Sumber : Data Primer Tahun 2018

Dari tabel 4.5 diatas dapat diketahui bahwa kekuatan otot pada kelompok intervensi sebelum diberikan intervensi memiliki nilai rata-rata 1,6 (SD:1,140) sedangkan nilai rata-rata kekuatan otot sesudah intervensi adalah 3 (SD:1,581). Sementara nilai rata-rata kekuatan otot pada kelompok kontrol di awal pemeriksaan adalah 1,6 (SD:1,140) dan nilai rata-rata kekuatan otot 6 hari adalah 2 (SD:1,225). 


\section{Analisa Bivariat}

Pada bagian ini akan disajikan hasil analisis perbedaan pengaruh Peningkatan fungsi kekuatan otot pada responden yang diberi Range Of Motion(ROM) dengan yang tidak diberikan ROM di Ruang Perawatan RSUD Kabupaten Polewali Mandar.

Tabel 4.6.Perbedaan PengaruhPeningkatan Fungsi Kekuatan Otot Ekstremitas Responden Sebelum dan Sesudah Dilakukan Intervensi Pada Kelompok Intervensi dan Kontrol di Ruang Perawatan RSUD Polewali Mandar

\begin{tabular}{llccccc}
\hline No & $\begin{array}{c}\text { Kelompok/ } \\
\text { Waktu }\end{array}$ & Mean & SD & SE & $\begin{array}{c}\text { Selisih } \\
\text { Mean }\end{array}$ & P \\
\hline 1 & $\begin{array}{l}\text { Intervensi } \\
\text { Sebelum }\end{array}$ & 1,6 & 1,140 & 0,510 & 1,4 & $\mathbf{0 , 0 0 5}$ \\
& $\begin{array}{l}\text { Sesudah } \\
2\end{array}$ & 3 & 1,581 & 0,707 & & \\
& Kontrol & & & & & \\
& Sebelum & 1,6 & 1,140 & 0,510 & 0,4 & $\mathbf{0 , 1 7 8}$ \\
\hline & Sesudah & 2 & 1,225 & 0,548 & \\
\hline
\end{tabular}

Sumber : Data Primer Tahun 2018

Dari tabel 4.6rata-rata kekuatan otot responden kelompok perlakuan pada pengukuran sebelum di berikan intervensi adalah 1,6 (SD:1,140) dan rata-rata kekuatan otot responden pada pengukuran sesudah diberikan intervensi adalah 3 (SD:1,581) sementara selisih dari mean sebelum dan sesudah intervensi adalah 1,4. Hasil uji beda dua mean di dapatkan nilai $\mathrm{p}$ value adalah 0,005 maka dapat disimpulkan bahwa adanya pengaruh yang signifikan antara kekuatan otot pada pengukuran sebelum dan sesudah di berikan intervensi Range Of Motion (ROM) pada kelompok intervensi.
Rata-rata kekuatan otot kelompok kontrol pada pengukuran di awal penelitian adalah 1,6 (SD:1,140) dan rata-rata kekuatan otot responden pada pengukuran sesudah 6 hari adalah 2 (SD:1,225) sementara selisih dari mean sebelum dan sesudah intervensi adalah 0,4. Hasil uji beda dua mean di dapatkan nilai $\mathrm{p}$ value adalah 0,178 maka dapat disimpulkan bahwa tidak ada pengaruh yang signifikan antara kekuatan otot pada pengukuran sebelum dan sesudah intervensi pada kelompok kontrol. 


\section{Pembahasan}

Stroke merupakan suatu keadaan yang timbul karena terjadi gangguan peredaran darah di otak yang menyebabkan terjadinya kematian jaringan otak sehingga mengakibatkan seseorang menderita kelumpuhan atau kematian (Batticaca, 2012).

Jenis stroke dalam penelitian ini ialah stroke iskhemia atau Non Hemoragik Stroke (NHS) yang terjadi pada pembuluh darah yang tersumbat, menyebabkan aliran darah ke otak sebagian atau keseluruhan terhenti disebabkan oleh aterosklerosis, yaitu penumpukan kolesterol pada pembuluh darah atau ada bekuan darah yang menyumbat suatu pembuluh darah ke otak (Pudiastuti, 2013).Stroke iskemik terjadi pada pembuluh darah yang mengalami sumbatan sehingga menyebabkan berkurangnya aliran darah pada jaringan otak, trombosis otak, aterosklerosis, dan emboli serebral yang merupakan penyumbatan pembuluh darah yang timbul akibat pembentukkan plak sehingga terjadi penyempitan pembuluh darah (Mutaqqin, 2011)

Menurut (Smeltzer \& Bare, 2010) pada stroke iskemik gejala utamnya adalah timbulnya defisit neurologis secara mendadak. Salah satu defisit neurologis ialah defisit/disfungsi motorik, Disfungsi motorik paling umum adalah paralisis pada salah satu sisi atau hemiparesis, serta kelumpuhan pada salah satu sisi tubuh atau hemiplegia karena lesi pada sisi otak yang berlawanan, dan menurunnya kekuatan otot secara perlahan.

Penatalaksanaan stroke dengan disfungsi motorik ialah dengan meningkatkan kekuatan dan tonus otot yaitu dengan melakukan Range of Motion (ROM).Range Of Motion (ROM) adalah jumlah pergerakan maksimum yang dapat di lakukan pada sendi, untuk mempertahankan atau memperbaiki tingkat kesempurnaan kemampuan menggerakan persendian secara normal dan lengkap bertujuan meningkatkan massa otot dan tonus otot (Potter \& Perry, 2010).

Dari hasil uji Statistik di dapatkan adanya peningkatan kekuatan otot ekstremitas yang signifikan pada kelompok intervensi di bandingkan dengan kelompok kontrol di lihat dari kelompok intervensi sebelum diberikan intervensi memiliki nilai rata-rata 1,6 (SD:1,140) sedangkan nilai rata-rata kekuatan otot sesudah ingtervensi adalah 3 (SD:1,581). Sementara nilai rata-rata kekuatan otot pada kelompok kontrol sebelum di berikan intervensi adalah 1,6 (SD:1,140) dan nilai rata-rata kekuatan otot sesudah intervensi adalah 2 (SD:1,225). Hasil dari uji Paired sample test di dapatkan bahwa perubahan pre-post test pada range of motion (ROM) untuk pemulihan kekuatan ototpada kelompok intervensi di dapatkan nilai $\mathrm{p}=0,005$ yang berarti ada pengaruh sebelum dan sesudah 
intervensi sedangkan pada kelompok kontrol yang tidak di berikan range of motion (ROM) di dapatkan nilai $\mathrm{p}=$ 0,175 yang berarti tidak ada pengaruh sebelum dan sesudah perawatan. Dapat dikatakan bahwa peningkatan kekuatan otot pasca stroke dengan pemberian range of motion (ROM) lebih efektif atau berpengaruh dalam peningkatan kekuatan otot daripada yang tidak diberikan range of motion (ROM) karena melihat batas nilai kemaknaan yaitu $\mathrm{p} \leq 0,05$, dimana nilai $\mathrm{p}=0,000<$ $\mathrm{p}=0,175$,

Dari hasil penelitian di atas dapat dikatakan dengan memberikan range of motion (ROM) kelemahan otot dapat teratasi. Hasil penelitian ini sesuai dengan teori Junaidi (2011) yang menyatakan bahwa setelah keadaan pasien membaik dan kondisinya telah stabil maka rehabilitasi dini dapat segera dilakukan di tempat tidur. Tujuan perawatan suportif dini adalah untuk memulai kegiatan yang memperbaiki fungsi saraf melalui terapi fisik dan teknik-teknik lain.

Hasil penelitian ini menunjukkan dengan range of motion (ROM) dapat mempertahankan dan memelihara felksibilitas dan kekuatan otot, memelihara mobilitas persendian dan mencegah kelainan bentuk, kekakuan dan kontraktur. Nilai kekuatan otot yang meningkat juga dapat memberi jawaban pada manfaat Range Of Motion (ROM) yaitu memperbaiki tonus otot, meningkatkan mobilisasi sendi, dan memperbaiki toleransi otot untuk latihan. Ekstremitas yang mengalami kelemahan atau kelumpuhan dalam derajat yang berbeda, tergantung pada bagian yang terkena dan seberapa luas sirkulasi serebral yang terganggu. Pasien stroke yang mengalami kondisi imobilisasi dalam jangka waktu lama akan memudahkan terjadinya berbagai komplikasi, diantaranya atrofi otot, kontraktur dan nyeri sendi, dan dekubitus. Latihan Range of Motion (ROM) merupakan salah satu bentuk latihan dalam proses rehabilitasi yang dinilai masih cukup efektif untuk mencegah terjadinya kecacatan pada pasien dengan stroke.

Hasil penelitian ini juga didukung oleh beberapa penelitian yaitu Penelitian yang dilakukan oleh Louis Ada. et all. (2015) tentang Thirty minutes of positioning reduces the development of shoulder external rotation contracture after stroke: A randomized controlled trialmendapatkan hasil bahwa memposisikan bahu untuk rotasi selama minimal 30 menit memberikan dampak positif pada perkembangan pergerakan minimal lengan

Penelitian yang dilakukan (Flansbjer.et all, 2008) tentang Progressive Resistance Training After Stroke: Effects on Muscle Strength, Muscle Tone, Gait Performance and Perceived Participation, mendapatkan hasil bahwa kekuatan ototmeningkat secara signifikan setelahlatihan ketahananprogresif.

Penelitian yang dilakukan oleh

Ruud W. Selles.et all.(2014) tentang 
Feedback-Controlled and Programmed Stretching of the Ankle Plantarflexors and Dorsiflexors in Stroke: Effects of a 4-Week Intervention Program yang mendapatkan hasil bahwa pergerakan sendi palntar dan dorsofleksi memberikan pengaruh yang positif bagi penderita stroke.

Penelitian yang dilakukan Oulette.et all.(2014) tentang HighIntensity Resistance Training Improves Muscle Strength, Self-Reported Function, and Disability in Long-Term Stroke Survivor, didapatkan hasil bahwa Progresive Intensive Training

\section{PENUTUP}

\section{Kesimpulan}

Data yang diperoleh dari hasil penelitian mengenai pengaruh Range of Motion (ROM) terhadap Peningkatan fungsi kekuatan otot pada pasien stroke di Ruang Perawatan RSUD Polewali Mandar adalah sebagai berikut :

Pada kelompok intervensi
Range of Motion (ROM) terdapat peningkatan kekuatan otot yang cukup signifikan sebelum dan sesudah intervensi dimana sebelum intervensi nilai rata-rata kekuatan otot 1,6 (SD:1,140) dan seetelah intervensi nilai rata-rata kekuatan otot 3 (SD:1,581) .

Pada kelompok control terdapat peningkatan kekuatan otot yang tidak signifikan di awal penelitian dan sesudah 6 hari penelitian di dimana sebelum penelitian nilai rata-rata kekuatan otot 1,6 memberikan dampak positif bagi perkembangan pergerakan pasien stroke.

Penelitian yang dilakukan oleh Rimmer JH. et all.(2009)tentang $A$ Preliminary Study to Examine the Effects of Aerobic and Therapeutic (Nonaerobic) Exercise on Cardiorespiratory Fitness and Coronary Risk Reduction in Stroke Survivors. Mendapatkan hasil bahwa terdapat perbedaan antara gerakan aerobic dan nonaerobic pada penurunan resiko reduksi jantung pada pasien stroke.

(SD:1,140) dan seetelah 6 hari penelitian nilai rata-rata kekuatan otot 2 (SD:1,225).

lebih berpengaruh pada pemberian intervensi Range of Motion (ROM) daripada yang tidak diberikan intervensi Range of Motion (ROM), dengan melihat batas nilai kemaknaan yaitu $p \leq 0,05$, dimana kelompok intervensi nilai $p=0,000$ ada pengaruh dan pada kelompok control $p=0,178$ tidak ada pengaruh.

\section{Saran}

Bagi Perawat

Peneliti mengharapkan agar perawat menganjurkan dan atau melakukan intervensi keperawatan Range Of Motion (ROM) pada pasien stroke yang mengalami hemiparases, tidak hanya bergantung pada proses fisioterapi di poliklinik rehabilitasi rumah sakit.

\section{Bagi RSUD Polewali Mandar}

Peneliti mengharapkan agar Rumah Sakit Umum Daerah Polewali 
mandar agar membuat SOP tentang ROM yang tetap terhadap pasien Stroke dengan penurunan fungsi motorik pada ekstremitas sehingga pelayanan kesehatan khususnya pelayanan keperawatan di ruang perawatan lebih maksimal.

\section{Bagi Institusi Pendidikan}

Peneliti mengharapkan agar hasil penelitian ini dapat dijadikan referensi pendukung secara ilmiah dalam penelitian dan keilmuan selanjutnya, dalam hal pengembangan ilmu keperawaatan khususnya keperawatan medikal Bedah.

\section{DAFTAR PUSTAKA}

Abd. Nasir, dkk. (2011). Buku Ajar Metodologi Penelitian Kesehatan : Konsep Pembuatan Karya Tulis dan Thesis untuk Mahasiswa Kesehatan. Yogyakarta: Nuha Medika.

Adi, Rian Pamungkas, A. M. U. (2017). Metodologi Riset Keperawatan. Jakarta: CV. Trans Info Media.

Alchuriyah \&Wahjuni (2016). Faktor resiko Kejadian Stroke Usia Muda pada Pasien Rumah Sakit Brawijaya Surabaya. Surabaya : Departemen Epidemologi Fakultas Kesehatan Masyarakat Surabaya.

Azis H. (2012).Pengantar Pendidikan Keperawatan.: Sagung Seto. Jakarta

\section{Bagi Profesi Keperawatan}

Peneliti mengharapkan agar mengadakan pengarahan kepada perawat agar meningkatkan kinerjanya dan melakukan penelitian dan pembelajaran, sehingga dapat menciptakan penemuan baru agar dapat menjadi agen pembaharu dalam dunia keperawatan khususnya keperawatan medikal bedah.

\section{Bagi peneliti selanjutnya}

Peneliti mengharapkan pada penelitian selanjutnya dapat melakukan studi mengenai faktor-faktor lain yang dapat meningkatkan kekuatan otot selain dari Range Of Motion (ROM).

Bastabie, Susan B. (2012). Perawat Sebagai Pendidik EGC. Jakarta

Beyer, Dudas, (2015). The Clinical Practice of Medical Surgical Nursing $2^{\text {nd }}$ Brown Co. Biston

Brunner \& Suddarth. (2011). Bedah Buku Ajar Medikal Vol 1 Ed 8 Penerbit Buku Kedokteran EGC Jakarta

Chandra, B (2015). Pengantar Statistik Kesehatan.: Penerbit Buku Kedokteran EGC Jakarta

Departemen Pendidikan dan Kebudayaan (2016).Kamus Dasar Bahasa Indonesia. Balai Pustaka. Jakarta.

Ester, Monica. (2011). Keperawatan Medikal Bedah : Pendekatan Sistem Gastro intestinal EGC. Jakarta

Esther, Joyce (2015). Medikal Surgical Nursing; clinical Management for 
Continuity of Care Fifth. Ed .W B. Saunders Philadelphia

Flansbjer, et all 2008 Progressive Resistance Training After Stroke: Effects on Muscle Strength, Muscle Tone, Gait Performance and Perceived Participation http://www.ingentaconnec t.com/content/mj1/sreh/2008/00000040/ 00000001/art00007_diunduh pada 10 Agusutus 2018

Herawani, I. at al.. (2011). Pendidikan Kesehatan Dalam Keperawatan. Jakarta : EGC.

Kozier. (2015 ) Fundamental of Nursing;Concepts,Process, and Practice Redwood City. California

Louise Ada, et.all, 2015. Thirty Minutes Of Positioning Reduces The Development Of Shoulder External Rotation Contracture After Stroke: A randomized controlled trialhttp://www.sciencedirect.com/scie nce/article/pii/S0003999304004289 diunduh pada 6 Agustus 2018

Luckmann and Sorensen's. (2013) Medical Surgical Nursing; A Psychophysiologic Approach W.B. Saunders Philadelphia

Michelle M. Ouellette, et.all, 2014. HighIntensity Resistance Training Improves Muscle Strength, Self-Reported Function, and Disability in Long-Term Stroke Survivors http://stroke.ahajournals.org/content/35 /6/1404. shortdiunduh pada 5 Agustus 2018
Nana S. Sukmadinata Prof.Dr.(2013) Landasan Psikologi Proses Pendidikan PT.Remaja Rosdakarya. Bandung

Nursalam (2013). Konsep \& Penerapan Metodologi Penelitian Ilmu KeperawwatanPedoman Skripsi, Tesis dan Instrumen Penelitian Keperawatan.: Salemba Medika. Jakarta

Notobroto (2014).Perhitungan Besar Sampel Lembaga Penelitian Universitas Airlangga. Surabaya.

Notoatmojo,S (2013) Pendidikan dan Perilaku Kesehatan Jakarta Rineka Cipta

Notoatmojo,S. (2015). Ilmu Kesehatan Masyarakat. Jakarta : Rineka Cipta.

Ruud W. Selles, et.all2014, FeedbackControlled and Programmed Stretching of the Ankle Plantarflexors and Dorsiflexors in Stroke: Effects of a 4Week Intervention Program,http://www.sciencedirect.com /science/article/pii/ S00039993050093 54 diuduh pada 5 Agusutus 2018

Singgih, S. (2014). Mengatasi Berbagai Masalah Statistik dengan SPSS versi 11,5 Jakarta. Elex Media Komputindo

Sugiono, Dr .(2013) Statistik untuk Penelitian. CV Alfabeta. Bandung

Suharsini, A. (2010) Prosedur Penelitian.Binarupa Aksara Jakarta.

Susan J. Garrison (2014).Dasar-dasar Terapi dan Latihan Fisik Hypocrates Jakarta 